\title{
Relating Water/Solute Permeability Coefficients to the Performance of Thin-Film Nanofiber Composite Forward Osmosis Membrane
}

\author{
Song Xiaoxiao ${ }^{1 *}$, Prince $\mathrm{JA}^{1}$ and Darren Delai Sun ${ }^{2}$
}

${ }^{1}$ Environmental \& Water Technology, Centre of Innovation, Ngee Ann Polytechnic, Singapore

${ }^{2}$ School of Civil and Environmental Engineering, Nanyang Technological University, Singapore

\begin{abstract}
The thin-film nanofiber composite (TNC) forward osmosis (FO) membranes are fabricated and systematically modified by a series of post treatments, such as adding additives into the monomer, $\mathrm{NaOH}$ treatment, chlorine treatment and support modification. The post treatments lead to the formation of modified membranes with a wide range of water permeability $(A)$ and solute permeability $(B)$ values. The impact of varied $A, B$ and $B / A$ values on the FO performance are systematically investigated. Furthermore, the value of $B / A$ is related to internal concentration polarization (ICP), external concentration polarization (ECP) and solute leakage, which are firstly proposed in this study. Compared with the Pressure Retarded Osmosis (PRO) orientation (i.e., active layer facing draw solution), the water flux is much lower at FO orientation (i.e., active layer facing feed solution) due to severe loss of effective osmotic pressure, which mainly results from the convective dilution and low mass transfer coefficient in support membrane (i.e., the D/S value). In addition to this, the coupled effect of solute leakage and low $D / S$ value also causes a minor loss of effective osmotic pressure. This is the first study to systematically analyze the B-A relationship of TNC membranes employing different modification techniques and to investigate the impact on the FO performance.
\end{abstract}

Keywords: Nanofiber composite membrane; Forward osmosis; Internal concentration polarization; External concentration polarization

\section{Introduction}

FO process is a low-energy process, which can potentially be applied in water/wastewater treatment and desalination [1]. In a typical FO process, the high-salinity draw solution is separated from the lowsalinity feed solution by a semi-permeable membrane. The membrane only allows water to pass through but rejects solutes [2-4]. The selectivity of FO membrane is crucial to maintain the osmotic pressure difference across the membrane. However, the permeability of FO membrane determines the water flux $\left(J_{W}\right)$ the membrane can harvest from preset osmotic pressure difference. Hydration Technologies Inc. (HTI) developed the first commercial flat sheet FO membrane. However the cellulose acetate based membrane has low FO flux because of severe internal concentration polarization (ICP) problem resulted from inefficient solute diffusion in the dense and tortuous membrane structure, additionally, the $\mathrm{NaCl}$ rejection is also not sufficient [1]. Later on, polyamide composite membranes have been developed by directly fabricating ultra-thin polyamide selective layers on porous polysulfone (PSU) or polyethersulfone (PES) support membranes. This design allows the individual optimization of active layer and support membrane to achieve high $\mathrm{NaCl}$ rejection while keeping resistance reasonably low [5]. These membranes can be fabricated either in hollowfiber forms [6], flat-sheet form [5,7-9], or resulted from modification of commercial RO membranes using polydopamine [10]. However, the above membranes rely on conventional phase inversion technology to form the support membranes, which results in structure parameter (S value) between 300-3000 $\mu \mathrm{m}$ [11]. Alternatively, thin-film nanofiber composite (TNC) FO membranes with S value as low as $100-150 \mu \mathrm{m}$ are the ideal candidate membranes to minimize ICP and harvest highest $J_{W}$ so far $[12,13]$. While methods to optimize the support membrane have been investigated by the above studies, fewer studies have touched on the optimization of separation abilities of polyamide selective layers $[5,11,14]$. The fabrication and post treatment methods of polyamide selective layers greatly influence water/solute permeability coefficients and determine the performance of polyamide TNC-FO membranes.
It has generally been understood that the membrane permeability has a trade-off relationship with membrane selectivity [11,15], indicating worse solute rejection at higher membrane permeability. Thus, a pressing need is to determine the relationship between water/solute permeability coefficients, which is a critical constraint for performance of TNC-FO membranes.

The main transportation phenomena, which govern the performance of FO membrane, are external concentration polarization (ECP), ICP and solute leakage [1]. The severity of the transportation phenomena was dependent on membrane intrinsic separation parameters (i.e., A and B value) and structure parameters (S value). Previous study stated that ICP associated with thick and dense support membrane was the main reason to cause flux decline in the HTI membranes [16]. Following that, numerous studies investigated the thin-film polyamide composite membranes in $\mathrm{FO}$ orientation (i.e. support membrane facing draw solution) [17]. They also attributed the substantially lower-than-ideal flux, $J_{W}^{F O}$ (i.e., FO water flux as membrane active layer facing feed solution), to ICP limitation. The severe ICP happens because the inefficient solute diffusion within the conventional phase-inversion support membrane cannot restore the dilution of draw solution by convective $J_{W}^{F O}$. However, the flux in PRO orientation, $J_{W}^{F O}$ (i.e., FO water flux as membrane selective layer facing draw solution), was found to be higher than the $J_{W}^{F O}$. This increment

*Corresponding author: Song Xiaoxiao, Environmental \& Water Technology, Centre of Innovation, Ngee Ann Polytechnic, Singapore, Tel: +65 97209056; E-mail: Song_xiaoxiao@np.edu.sg

Received November 14, 2016; Accepted December 08, 2016; Published December 15, 2016

Citation: Xiaoxiao S, Prince JA, Sun DD (2016) Relating Water/Solute Permeability Coefficients to the Performance of Thin-Film Nanofiber Composite Forward Osmosis Membrane. J Membra Sci Technol 6: 160. doi:10.4172/21559589.1000160

Copyright: @ 2016 Xiaoxiao S, et al. This is an open-access article distributed under the terms of the Creative Commons Attribution License, which permits unrestricted use, distribution, and reproduction in any medium, provided the original author and source are credited. 
was attributed to less severe ECP when dilution happens in bulk solution (PRO orientation). Because the cross flow facilitates solute diffusion and reliefs the convective dilution. In addition, the leaked solutes from draw solution into support membrane were believed to accumulate along the direction of convective $J_{W}^{P R O}$, resulting in accumulative ICP [16]. However, the analysis results about the phenomena have not been quantified. Neither have the transportation phenomena been related to membrane intrinsic separation parameters (i.e. A and B values). Thus, the elucidation about comparative contribution of above transportation phenomena to limitation of FO performance, especially in the TNC membranes with low $\mathrm{S}$ value, is lacking.

The objective of this study is to relate the membrane intrinsic parameters to TNC membranes performance. More specifically, TNC membranes were fabricated with varied hydrophobicity of support membrane [18], IP additives [19], post treatment methods [11] and nonwoven substrate [20]. A series of A-B pairs were resulted from above approaches. ICP index (I) and ECP index (E) are defined to quantify the contribution of ICP, ECP and solute leakage to the loss of effective osmostic pressure difference ( $\Delta \pi_{\text {eff }}$ ) due to these phenomena. The relationship between the membrane intrinsic separation parameters and the severity of ICP/ECP are then systematically analyzed. This approach helps to guide the general design of cost-effective polyamide FO membrane to maximize the $J_{W}^{F O}$ while maintaining affordable solute leakage.

\section{Theory}

According to definition, ICP either results from building up of feed solute concentration within support membrane in PRO orientation [21] or dilution of draw solute concentration within support membrane in FO orientation [7]. However, the real concentration at the interface of selective layer and support membrane cannot be directly measured [21]. Thus, indexes should be derived to indicate the severity of ICP. Water flux (JW) across the thin film composite FO membrane is given by [21].

$$
J_{W}=A^{*} \Delta \pi_{m}=A^{*}\left(\pi_{D, m}-\pi_{F, m}\right)
$$

wherein $\mathrm{A}$ is the intrinsic water permeability coefficient of the membrane, $\Delta \pi_{m}$ is the effective osmotic pressure difference across membrane selective layer. Salt flux $\left(J_{s}\right)$ is given by [22].

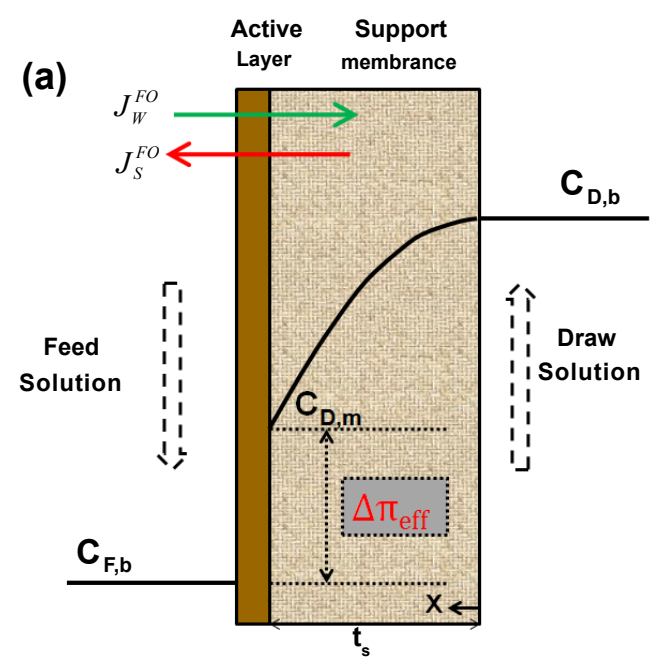

$$
J_{S}=B\left(C_{D, m}-C_{F, m}\right)
$$

wherein B is the salt permeability coefficient, $C_{F, m}$ and $C_{F, m}$ are salt concentration at selective layer surfaces on draw solution side and feed solution side respectively. Van't hoff equation can be applied to relate the $\mathrm{NaCl}$ concentration to osmotic pressure [23].

$$
\pi=n R_{g} T * C
$$

Taking the ratio of equation (1) and (2) yields [24]:

$$
J_{W} / J_{S}=A / B * n R_{g} T
$$

Equation (4) is valid to thin film composite membranes, which comply with the solution-diffusion theory [14]. Or, the modeled water flux over reverse salt flux is linearly related to intrinsic water permeability coefficient over salt permeability coefficient.

Considering the mass transfer in FO membrane support membrane (Figure 1), the salt flux is the sum up of two terms: salt diffusion from local salt concentration gradient and dilution by convective $J_{W}$ $[21,23,24]$. Thus, the mass transfer equations in FO orientation and PRO orientation can be written as equation (5) and (6), respectively.

$$
\begin{aligned}
& J_{S}^{F O}=-D_{e f f} d C(x) / d x+\left(-J_{W}^{F O} C(x)\right) \\
& J_{S}^{P R O}=D_{e f f} d C(x) / d x+\left(-J_{W}^{P R O} C(x)\right)
\end{aligned}
$$

The boundary conditions for equations (5) are: at $x=0, C(x)=C_{F, b} ; \quad$ and at $x=0, C(x)=C_{F, b}$. Boundary conditions for equation (6) are: at $x=0, C(x)=C_{F, b}$; and at $x=t_{S}, C(x)=C_{F, m}$. Solving equations (5) and (6) using above boundary conditions respectively yields:

$$
\begin{aligned}
& C_{D, m}=C_{D, b} \exp \left(-J_{F O} S / D\right)-J_{S} / J_{W}\left(1-\exp \left(-J_{F O} S / D\right)\right) \\
& C_{F, m}=C_{F, b} \exp \left(J_{P R O} S / D\right)+J_{S} / J_{W}\left(\exp \left(J_{P R O} S / D\right)-1\right)
\end{aligned}
$$

Above equations reveal that actual salt concentrations at the selective layer-support membrane interface at both FO configuration and PRO configuration are determined by two terms: convective flow term and solute leakage term [21].

Here, we define the $\Delta \pi_{\text {eff }}$ loss to ICP in support membrane

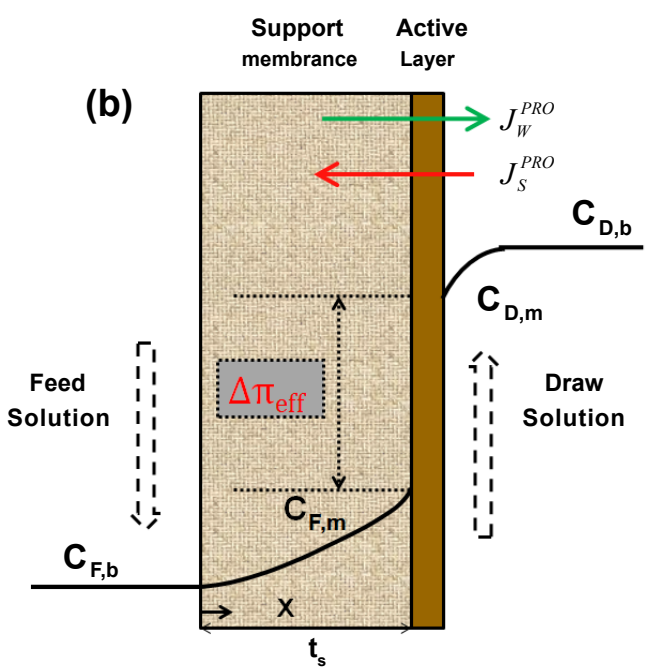

Figure 1: Schematic drawing of solute concentration profile across a TNC membrane at: a) FO orientation and b) PRO orientation. 
over apparent driving force as the ICP index (I). The ICP index can be calculated based on its definition and equation (7) and (8):

$$
\begin{aligned}
& I_{F O}=\frac{C_{D, b}-C_{D, m}}{C_{D, b}-C_{F, b}}=\frac{1}{C_{D, b}-C_{F, b}} *\left(C_{D, b}+\frac{B}{A^{*} n R_{g} T}\right) *\left(1-\exp \left(-J_{W}^{F O} S / D\right)\right) \\
& I_{P R O}=\frac{C_{F, m}-C_{F, b}}{C_{D, b}-C_{F, b}}=\frac{1}{C_{D, b}-C_{F, b}} *\left(C_{F, b}+\frac{B}{A^{*} n R_{g} T}\right) *\left(\exp \left(J_{W}^{P R O} S / D\right)-1\right)
\end{aligned}
$$

In the PRO orientation, the negative dilution effect of convective water flux $J_{W}^{P R O}$, which happens externally can be similarly defined as the ECP index [21]:

$$
E_{P R O}=\frac{C_{D, b}-C_{D, m}}{C_{D, b}-C_{F, b}}=\frac{1}{C_{D, b}-C_{F, b}} *\left(C_{D, b}+\frac{B}{A^{*} n R_{g} T}\right) *\left(1-\exp \left(-J_{W}^{P R O} / k\right)\right)
$$

Equation 9 to 11 relates the $\mathrm{CP}$ indexes, $I_{F O}, E_{P R O}$ and $I_{P R O}$ to intrinsic parameters of membrane ( $\mathrm{A}, \mathrm{B}$ and $\mathrm{S}$ values). In $\mathrm{FO}$ orientation, the dilution of draw solution locates inside support membrane, thus the $I_{F O}$ is a sum up of two terms: the first term, $C_{D, b} *\left(1-\exp \left(-J_{W}^{F O} S / D\right) /\left(C_{D, b}-C_{F, b}\right)\right.$, represents the coupled effect of diluted draw solution by convective $J_{W}^{F O}$ and support membrane resistance to diffusion (S/D); while the second term, $\quad B *\left(1-\exp \left(-J_{W}^{F O} S / D\right)\right) /\left(A * n R_{g} T *\left(C_{D, b}-C_{F, b}\right)\right)$, represents the coupled effect of solute leakage with the convective dilution. In PRO orientation, the dilution of draw solution locates in the bulk solution, thus the $E_{P R O}$ is a sum up of two similar terms: the first term $C_{D, b} *\left(1-\exp \left(-J_{W}^{P R O} / k\right)\right) /\left(C_{D, b}-C_{F, b}\right)$, represents the convective dilution in the bulk solution, while the second term, $\quad B *\left(1-\exp \left(-J_{W}^{P R O} / k\right)\right) /\left(A^{*} n R_{g} T *\left(C_{D, b}-C_{F, b}\right)\right)$, represents the coupled effect of solute leakage with the convective dilution by $J_{W}^{P R O}$. This is a sum up of two terms: the first term $C_{F, b} *\left(\exp \left(J_{W}^{P R O} S / D\right)-1\right)\left(C_{D, b}-C_{F, b}\right)$, represents the coupled effect of accumulated draw solution by convective $J_{W}^{P R O}$ and support membrane resistance to diffusion (S/D); while the second term, $B *\left(\exp \left(J_{W}^{P R O} S / D\right)-1\right) /\left(A * n R_{g} T *\left(C_{D, b}-C_{F, b}\right)\right)$, represents the coupled effect of solute leakage and the convective accumulation.

\section{Experiment}

\section{Electrospinning of nanofiber support membrane}

PAN nanofiber support membranes were electrospun-bound from $8 \% \mathrm{w} / \mathrm{w}$ PAN $\left(\mathrm{Mw}=150,000 \mathrm{~g} \mathrm{~mol}^{-1}\right)$ solution in N,N-Dimethyl Formamide (DMF), using a custom-built device [12]. The optimum concentration of $8 \%$ was chosen to avoid spraying droplets (low concentration) and thick fibers (high concentration). The solution was mixed for at least 24 hours at $80^{\circ} \mathrm{C}$ before use. Nanofibers were formed by drying out from continuously elongated viscous polymer solution jet in electrical field. Typically, a DC voltage of $30 \mathrm{kv}$ was applied between an stainless steel (SS) spinneret orifice $(\mathrm{D}=0.7 \mathrm{~mm})$ and a SS rotating drum $(300 \mathrm{rpm}) 15 \mathrm{~cm}$ beneath the orifice. A horizontally oscillating actuator $\left(60 \mathrm{~cm} \mathrm{~min}^{-1}\right)$ drove the rotating drum simultaneously. Prior to electrospining, the stainless steel rotating drum (Length $\times$ Diameter $=20 \mathrm{~cm} \times 10 \mathrm{~cm}$ ) was wrapped with a Poly (ethylene terephthalate) (PET) non-woven substrate (Ahlstrom Grade 3249) pre-wetted with NMP (Acros organics). The PAN solution was fed to the spinneret with a constant speed of $40 \mu \mathrm{l} \mathrm{min}{ }^{-1}$. Dispersed nanofibers were spun-bounded and assembled into a nascent nanofiber support membrane on the rotating drum. The nascent nanofiber support membrane was sandwiched between two pieces of clear glass $\left(10 \mathrm{~mm}\right.$ thick) and heat treated at $120^{\circ} \mathrm{C}$, resulting in final nanofiber support membrane. Chemicals (if not specified) were purchased from Sigma Aldrich.

\section{Modification of nanofiber support membrane}

A part of PAN nanofiber support membranes were treated with 1.5 $\mathrm{M} \mathrm{NaOH}$ (Merck) at $60^{\circ} \mathrm{C}$ for $1 \mathrm{~h}$. The nitrile group on the side chains of PAN readily hydrolyses to form - $\mathrm{COOH}$ [25].

\section{Interfacial polymerization}

Interfacial polymerization (IP) was performed on surfaces of the electrospun support membranes. The nanofiber support membranes were immersed into isopropanol for better wetting ability prior to IP. The IP recipe was adpoted from literature with some modifications [19]: Support was taped to a piece of glass with four sides sealed, and then soaked in 3\% m-Phenylenediamine (MPD) aqueous solution (with or without triethylamine (TEA, $1.1 \% \mathrm{v} / \mathrm{w}$ ) and camphor sulfonic acid $(\mathrm{CSA}, 2.3 \% \mathrm{w} / \mathrm{w})$ ) for 2 minutes. Air knife (operated at $0.2 \mathrm{Bar}, 10 \mathrm{~mm}$ away from support membrane surface) was used to drain excess MPD solution from saturated nanofiber support membranes until surfaces became dull. Then, $0.15 \% \mathrm{w} / \mathrm{w}$ trimesoyl chloride (TMC) in hexane was poured onto the MPD saturated support membranes. After 1 minute reaction, the nascent composite membrane was cured at $105^{\circ} \mathrm{C}$ in oven for 2 minutes. Then the stabilized TNC membranes were substantially washed with DI water and kept at $5^{\circ} \mathrm{C}$ in DI water until further tests were conducted.

\section{Chlorine modification of polyamide active layer}

The $\mathrm{NaClO}$ modification is related to $\mathrm{NaClO}$ concentration, exposure time, $\mathrm{pH}$ value and post treatment. In this work, the modification conditions are chosen based on previous publications [26]. Briefly, sodium hypochlorite (4\%-4.99\%) aqueous solution was diluted by 40 times ( 1000 ppm) and 20 times ( $2000 \mathrm{ppm})$. The $\mathrm{pH}$ of the diluted $\mathrm{NaClO}$ solutions were adjusted to $7.0 \pm 0.2$ with $6 \mathrm{M}$ $\mathrm{HCl}$. Membranes treated with $1000 \mathrm{ppm} \mathrm{NaClO}$ were immersed in $0.1 \mathrm{M} \mathrm{NaOH}$ solution for $14 \mathrm{~h}$ subsequently. Membranes treated with $2000 \mathrm{ppm} \mathrm{NaClO}$ were immersed in $0.1 \mathrm{M} \mathrm{NaOH}$ solution for $48 \mathrm{~h}$ subsequently. Next the treated membranes were washed with DI water extensively, cured again at $95^{\circ} \mathrm{C}$ for 2 minutes and kept in $5^{\circ} \mathrm{C}$ DI water before further experiment.

\section{Designation of membranes}

The membranes subject to one or two of the above modification methods are summarized and designated in following table. The "MPD+TMC" refers to IP recipe without additives during fabrication. The "substrate removal" refers to removal of PET non-woven substrate

\begin{tabular}{|c|c|c|c|c|c|c|}
\hline $\begin{array}{l}\text { Membrane } \\
\text { Designation }\end{array}$ & $\begin{array}{l}\text { MPD } \\
+ \text { +TMC }\end{array}$ & $\begin{array}{c}\mathrm{NaOH} \\
\text { Treatment }\end{array}$ & $\begin{array}{l}\text { Amine } \\
\text { Additive }\end{array}$ & $\begin{array}{c}\text { NaClO } \\
\text { Wash } \\
\text { (1000ppm) }\end{array}$ & $\begin{array}{c}\text { NaClO } \\
\text { Wash } \\
\text { (2000ppm) }\end{array}$ & $\begin{array}{l}\text { Substrate } \\
\text { Removal }\end{array}$ \\
\hline TNC-1 & $\sqrt{ }$ & & & & & \\
\hline TNC-2 & & $\sqrt{ }$ & & & & \\
\hline TNC-3 & & & $\sqrt{ }$ & & & \\
\hline TNC-4 & & & $\sqrt{ }$ & $\sqrt{ }$ & & \\
\hline TNC-5 & & & & $\sqrt{ }$ & & \\
\hline TNC-6 & & & & & $\sqrt{ }$ & \\
\hline TNC-7 & & & & & & $\sqrt{ }$ \\
\hline TNC-8 & & $\sqrt{ }$ & & & & $\sqrt{ }$ \\
\hline
\end{tabular}
before any test of performance. The procedures of other three categories can be found in above experimental sub-sections (Table 1). 
Citation: Xiaoxiao S, Prince JA, Sun DD (2016) Relating Water/Solute Permeability Coefficients to the Performance of Thin-Film Nanofiber Composite Forward Osmosis Membrane. J Membra Sci Technol 6: 160. doi:10.4172/2155-9589.1000160

\section{Determination of water permeability coefficient}

Water permeability coefficient (A) is determined by a bench scale cross-flow RO unit [12]. Spacers (sterlitech, Sepa CF feed spacer, 17 mil) were inserted. The cross flow velocity $(\mathrm{CFV})$ was $15 \mathrm{~cm} / \mathrm{s}$. The loaded membrane was subject to pure water compaction at $10 \mathrm{Bar}$ for at least $3 \mathrm{~h}$ before conduction of experiment. Then the pressure was lowered down to a series of values $(\Delta \mathrm{P})$ and the corresponding pure water flux $J_{W}^{R O}$ was measured. A is the slope by linear fitting $\Delta \mathrm{P}$ as a function of $J_{W}^{R O}\left(\Delta \mathrm{P}=\mathrm{A}^{*} J_{W}^{R O}\right)$ [7].

\section{Determination of membrane performance in FO orientation}

$0.5-2 \mathrm{M} \mathrm{NaCl}$ and $\mathrm{DI}$ water $(\mathrm{CF}, \mathrm{b} 0 \approx 0)$ was employed as draw solution and feed solution respectively. The nanofiber membrane was loaded in a custom-built FO module (effective membrane area $=23.76$ $\mathrm{cm}^{2}$ ), with support membrane facing draw solution (FO orientation) and active layer facing feed solution. The schematic diagram of the FO module was shown in Figure A1 (Appendix). Spacers (Sepa CF feed spacer, 17 mil thickness) were set in the $2 \mathrm{~mm}$ deep troughs on both of feed and draw sides. CFV on both feed and draw side was maintained at $16.7 \mathrm{~cm} \mathrm{~s}^{-1}$. While equilibrium was reached, the conductivity and weight change of feed and draw solutions were continuously monitored and logged into computer every 2 minutes. The $J_{W}^{F O}$ and $C_{F, b}$ can be derived from the monitored data [12].

Determination of solute permeability coefficient (B) and membrane structure parameter (S)

The salt permeability $(B)$ and structure parameter $(S)$ was calculated based on FO water flux, $J_{W}^{F O}$, and FO solute flux, $J_{S}^{F O}$. As such, according to mass balance equation:

$$
C_{F, b}\left(V_{0}-J_{W}^{F O} * A_{m} * t\right)=C_{F, b 0} * V_{0}+J_{S}^{F O} * A_{m} * t
$$

Wherein $C_{F, b}$ is the bulk feed solute concentration at time $t$. $V_{0}$ is the original feed solution volume. $A_{m}$ is the membrane area and $C_{F, b 0}$ is the initial bulk feed solute concentration. $J_{S}^{F O}$ is the FO solute flux, which can be rewritten as [11]:

$$
J_{S}^{F O}=B^{\star} C_{d, b}{ }^{*} \exp \left(-J_{W}^{F O} S / D\right)
$$

Wherein $C_{D, b}$ is the bulk draw solute $(\mathrm{NaCl})$ concentration, $D$ is the solute diffusion coefficient [27]. $S$ is the membrane structure parameter, which can be calculated from Equation 14 [12]:

$$
S=\left(D / J_{W}^{F O}\right) * \ln \left(\left(B+A * \pi_{D, b}\right) /\left(B+J_{W}^{F O}\right)\right)
$$

Wherein $\pi_{D, b}$ is the osmotic pressure of bulk draw solute $(\mathrm{NaCl})$. The above equation 1, 2 and 3 have three unknown variables, thus $J_{S}^{F O}, B$ and $S$ can be solved.

\section{Determination of membrane performance in PRO orientation}

Keeping all other parameters the same with the test in FO orientation, the PRO orientation refers to the reverse membrane orientation-polyamide active layer facing draw solution (PRO orientation) and porous nanofiber support membrane facing feed solution. Accordingly, the water flux in PRO orientation, $J_{S}^{P R O}$ and solute flux in PRO orientation, $J_{S}^{P R O}$ can be derived from the monitored data.

\section{Membrane characterization}

Micro-images were obtained employing a Zeiss Evo 50 Scanning
Electron Microscopy (SEM). High resolution SEM images were obtained using a Joel JSM-7600F thermal field emission SEM (FESEM). Exposed cross-sections were obtained by fracturing the samples immediately after flash-freezing by liquid nitrogen. An EMITECH SC7620 sputter coater was utilized to coat all samples with gold for 45-60 seconds.

\section{Results and Discussion}

\section{Membrane structure and morphology}

Figure 2 shows the comparison between FESEM images showing top surfaces of phase-inversion support membrane (left) and nanofiber support membrane (right), respectively. Compared with nanofiber support membrane, phase inversion support membrane showed smaller and tortuous pores on the surface. The narrow and tortuous pores in the nano-range results in overall low surface porosity [28]. This pore-structure of support membrane is not favorable for: i) the diffusion of draw solutes, and ii) the contact between draw solution and selective layer, thus is not the best candidate for FO applications [12]. By contrast, the nanofiber membranes have a uniformly distributed porosity of near $80 \%$ along the entire support membrane thickness, favoring the contact between draw solution and selective layer $[12,13]$. Furthermore, the inter-connected and less-tortuous pore structure is favorable for convective solute diffusion and thus alleviates ICP within the support membrane.

Figure 3 shows SEM images of surfaces of TNC-1, TNC-3, TNC-5 and TNC-6 membranes (a-d) and typical cross section image of TNC membranes (e-f). After IP was performed, surfaces of the nanofiber support membrane have been bonded with a dense polyamide layer. The morphology of the polyamide layer is typically "ridge and valley" characteristics of rough IP surface (Figure 2a). By visual observation from the SEM image, numerous "leaf-like" structures appear at the surface. With the addition of amine (TEA), the leaf-like structures can hardly be seen and the surface shows smoother and "nodular-like" morphology (Figure 2b). Similar observation has been found by Ghosh et al. [19]. When the TNC membrane is treated with $1000 \mathrm{ppm}$ and $2000 \mathrm{ppm} \mathrm{NaClO}$, the surface becomes rougher as more "leaf-like" micro-structures, can be observed in the SEM image with the same magnification (Figure $2 \mathrm{c}$ and $2 \mathrm{~d}$ ). The change of surface morphology has been linked with possible change of membrane performance in previous publications [29]. The cross-section view of the membrane presents a thin and dense polyamide active layer been successfully synthesized and closely bonded with the nanofiber support membrane (Figure 2e and 2f).

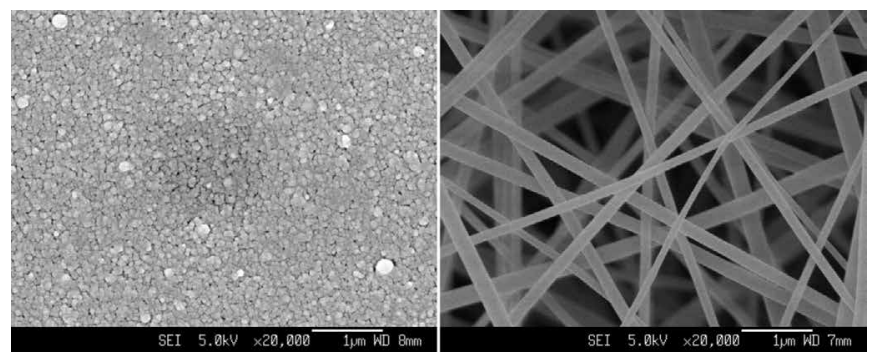

Figure 2: Top surface FESEM images of phase-inversion resulted PAN support membrane (left) and electrospun PAN nanofiber support membrane (right). 

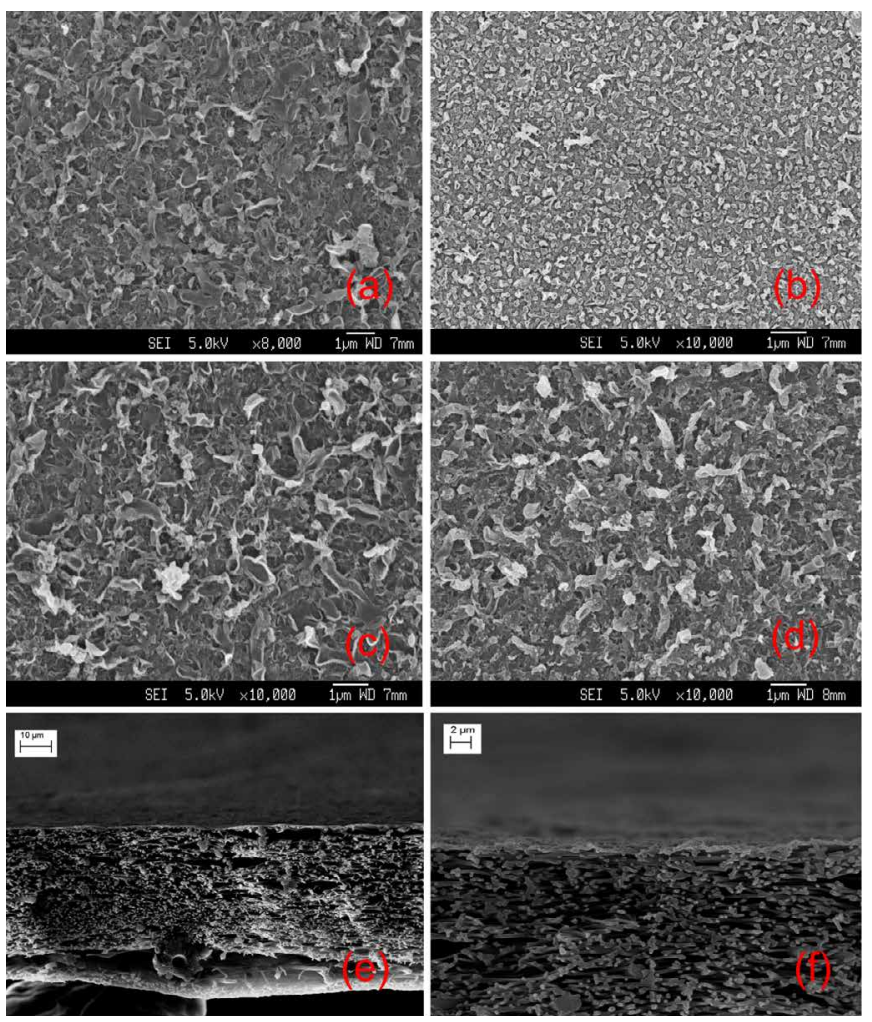

Figure 3: SEM images showing: top surfaces of (a) TNC-1 membrane; (b) TNC-3 membrane with TEA as additive; (c) TNC-5 membrane with $1000 \mathrm{ppm}$ $\mathrm{NaClO}$ treatment; (d) TNC-6 membrane with $2000 \mathrm{ppm} \mathrm{NaClO}$ treatment and cross-sections of typical TNC membrane (e-f).

Factors that influences permeability coefficients ( $A$ and $B$ value) in TNC-FO membranes

Role of hydrophilicity of nanofiber support membrane: Hydrophobicity of membrane support membrane inhibits the membrane wetting ability and exacerbates ICP [18]. In our previous work, the unique pore structure of nanofiber support membranes have been proven to favor the water to pass through the membrane and alleviates the ICP $[12,30]$. However, the impact of hydrophobicity of nanofiber support membrane on the FO performance of TNC membranes has not been studied [31-33].

In this work, PAN, a polymer with alterable hydrophobicity and widely been used to fabricate commercial ultrafiltration (UF) membranes, was selected to fabricate the nanofiber support membrane [31,34]. Figure 4 shows the comparison of FT-IR adsorption spectrums before and after alkali treatment. Peaks at $1452 \mathrm{~cm}^{-1}$ and $2243 \mathrm{~cm}^{-1}$ are the characterization absorption peaks of PAN, attributing to stretching of $-\mathrm{C} \equiv \mathrm{N}$ and bending of $-\mathrm{CH} 2$ respectively. Strong new adsorption peaks at $1569 \mathrm{~cm}^{-1}$ and $1405 \mathrm{~cm}^{-1}$ (overlapped with $1452 \mathrm{~cm}^{-1}$ ) indicates the formation of carboxylic groups during hydrolysis of PAN [34,35]. Concurrently, contact angle has been reduced from $41^{\circ}$ to $11^{\circ}$ upon the alkali treatment (Figure 4, inserted pictures). The colour of the support membrane turned from white to golden yellow through the treatment. Similar observations of hydrophilicity increase upon alkali modification have been found in PAN phase-inversion membranes $[34,35]$. It has been revealed that the alkali treatment is an efficient solution to enhance the hydrophilicity of PAN because of efficient conversion of $-\mathrm{C} \equiv \mathrm{N}$ groups to $-\mathrm{COOH}$ groups [36]. The membrane intrinsic parameters of membranes before and after hydrolysis are plotted in Figure 5. As support membrane b treated by $\mathrm{NaOH}$ (TNC2), the A value of membrane increased from $1.23 \pm 0.08 \mathrm{~L} \mathrm{~m}^{-2} \mathrm{~h}^{-1} \mathrm{bar}^{-1}$ to $1.39 \pm 0.12 \mathrm{~L} \mathrm{~m}^{-2} \mathrm{~h}^{-1}$ bar $^{-1}$ while the $\mathrm{B}$ and $\mathrm{S}$ values were maintained at nearly the same level. Note that the alkali treatment does not alter the structure of the PAN nanofiber membrane, thus the change of FO performance upon alkali treatment should be attributed to the enhancement of hydrophilicity. After removal of PET non-woven substrate (TNC-8), the A value further increases to $1.43 \pm 0.10 \mathrm{~L} \mathrm{~m}^{-2}$ $\mathrm{h}^{-1}$ bar $^{-1}$.

Role of IP additive in the selective layer: Additives into interfacial polymerization recipe substantially influence the polyamide active layer morphology and membrane intrinsic separation parameters $[19,29]$. The intrinsic parameters of membranes with (TNC-3) or without (TNC-1) additives are compared in Figure 6. Also, the $\mathrm{NaClO}$ post-treated membranes with (TNC-4) without (TNC-5) additives are

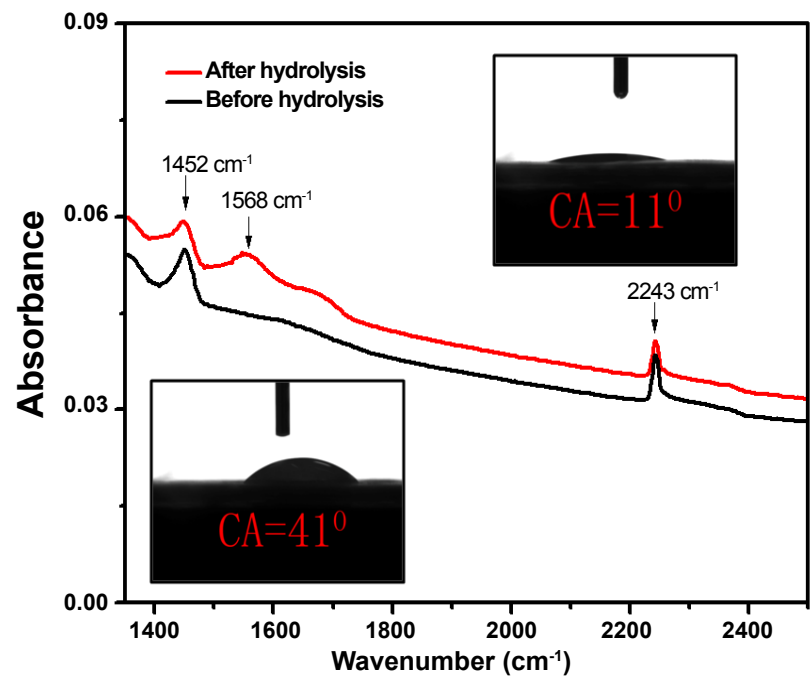

Figure 4: FT-IR adsorption spectrums before (black line) and after (red line) alkali treatment. Inserted images show the according contact angle.

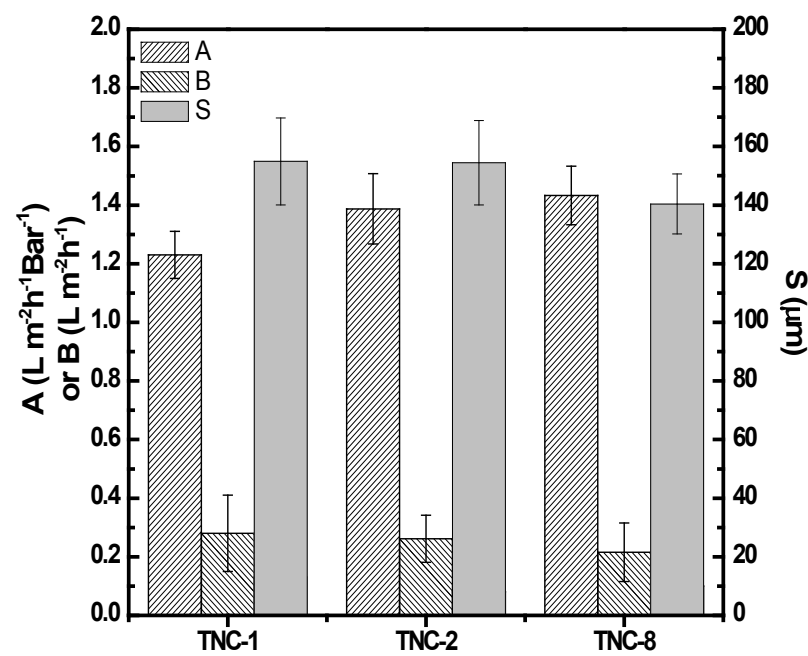

Figure 5: The membrane intrinsic parameters of TNC membranes before (TNC-1), after hydrolysis (TNC-2) and further removal of PET nonwoven substrate (TNC-8). 


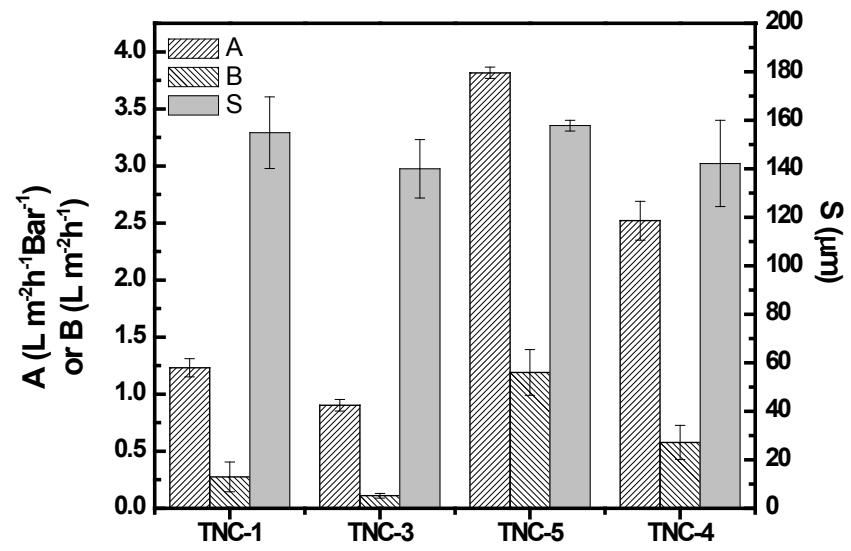

Figure 6: The membrane intrinsic parameters of TNC membranes fabricated without TEA (TNC-1 and TNC-5) or with TEA (TNC-3 and TNC-4).

compared in the same figure. In both cases, membranes fabricated with TEA-CSA as additives have lower A, B and B/A values compared with that without the additive. When membranes were not treated with $\mathrm{NaClO}$, the addition of the TEA-CSA decreased $\mathrm{B} / \mathrm{A}$ from the value of 0.28 to 0.11 . When membranes were treated with $1000 \mathrm{ppm} \mathrm{NaClO}$, the TEA-CSA decreased B/A from 0.31 to 0.23 . Lower B/A values indicate better ability for membrane to separate water and solutes [14]. The TEA is generally believed to facilitate IP reactions by releasing free amine groups and neutralizing $\mathrm{HCl}$ produced [19,37]. The function of CSA is likely to prevent the microstructures in the polyamide layer from collapsing during the high temperature curing [19]. It has been shown in Figure $2 \mathrm{~b}$ that the addition of TEA in IP recipe results in a smoother "nodular-like" morphology, this feature may relate to its lower water and solute permeability, as shown by a previous study of polyamide membranes [29].

Role of chlorine modification of membrane selective layer: A series of water permeabilities can be obtained by treatment applying different concentration of $\mathrm{NaClO}$ [21]. It is found recently that a combination of $\mathrm{N}$-chlorination and hydrolysis processes can result in the increase of membrane permeability $[38,39]$. The chlorine treatment increases water permeability at the expense of some salt passage. The "trade-off" relationship between water permeability and solute permeability has been studied by several studies [11,15,40]. Study of the relationship between water/solute permeability gives insightful knowledge to optimize membrane for various FO applications. In Figure 7 , the membrane treated with mild conditions of chlorine, designated as "TNC-5", has tripled A value $\left(3.82 \mathrm{~L} \mathrm{~m}^{-2} \mathrm{~h}^{-1} \mathrm{bar}^{-1}\right)$ compared to membranes with no $\mathrm{NaClO}$ treatment (TNC-1, $1.23 \mathrm{~L} \mathrm{~m}^{-2}$ $\mathrm{h}^{-1}$ bar $\left.^{-1}\right)$. The trade-off is the quadrupled B value of TNC-5 $\left(1.19 \mathrm{~L} \mathrm{~m}^{-2}\right.$ $\left.\mathrm{h}^{-1}\right)$ compared to TNC-1 $\left(0.28 \mathrm{~L} \mathrm{~m}^{-2} \mathrm{~h}^{-1}\right)$. The harsher chorine treatment yields even higher $A$ and $B$ value of $5.31 \mathrm{~L} \mathrm{~m}^{-2} \mathrm{~h}^{-1}$ bar $^{-1}$ and $3.86 \mathrm{~L} \mathrm{~m}^{-2}$ $\mathrm{h}^{-1}$ respectively. This result is consistent with previous publications that $\mathrm{NaClO}$ is effective to enhance water permeability of polyamide layer $[21,38]$. Note that as A value increases, B value increases much faster. The trade-off relationship is discussed in the following section.

Role of PET non-woven substrate: The thick and dense nonwoven PET substrates for pressure-driven membranes, such as reverse osmosis membranes, were considered to cause substantial water flux loss in osmotically-driven processes $[18,20]$. Alternatively, thinner and more porous non-woven PET substrate has been used for higher performance [7]. In this study, the role of PET substrate on FO membrane is also investigated (Figure 8). After carefully removal of non-woven substrate, the A value was increased from $1.23 \mathrm{~L} \mathrm{~m}^{-2} \mathrm{~h}^{-1} \mathrm{bar}^{-1}$ (TNC-1) to $1.41 \mathrm{~L} \mathrm{~m}^{-2} \mathrm{~h}^{-1} \mathrm{bar}^{-1}$ (TNC-7).

\section{Trade-off relationship of membrane intrinsic water permeability and solute permeability}

In previous studies, it has been proposed that $B$ is linearly related with $A^{3}$ for polyamide membranes $[11,15]$. Membranes with higher $A$ value facilitates the clean water production at a higher rate and thus is land-saving; however, subject to the trade-off relationship, the concurrent increases of $B$ value result in more severe leakage of draw solutes. Thus, the efficiency of the FO system is determined by the design of FO membrane to achieve high $A$ value while maintaining affordable $B$ value. $A$ and $B$ values of all TNC membranes are plotted in Figure 9. It was found that all the $A-B$ pairs can be fitted with the function of $B=K^{*} A^{3}\left(k=0.025 \mathrm{bar}^{3} m^{4} h^{2} L^{-2}\right)$. Note that the above "tradeoff" relationship can be re-arranged to be: $B / A=K^{*} A^{2}$. This implies that any attempt to increase the water permeability will suffer from concurrently increase $B / A$ value and sacrifice the selectivity. The $B / A$ value have been employed to indicate the selectivity of membrane [14]. Thus in this paper, $B / A$ is employed as the main variable to reflect the

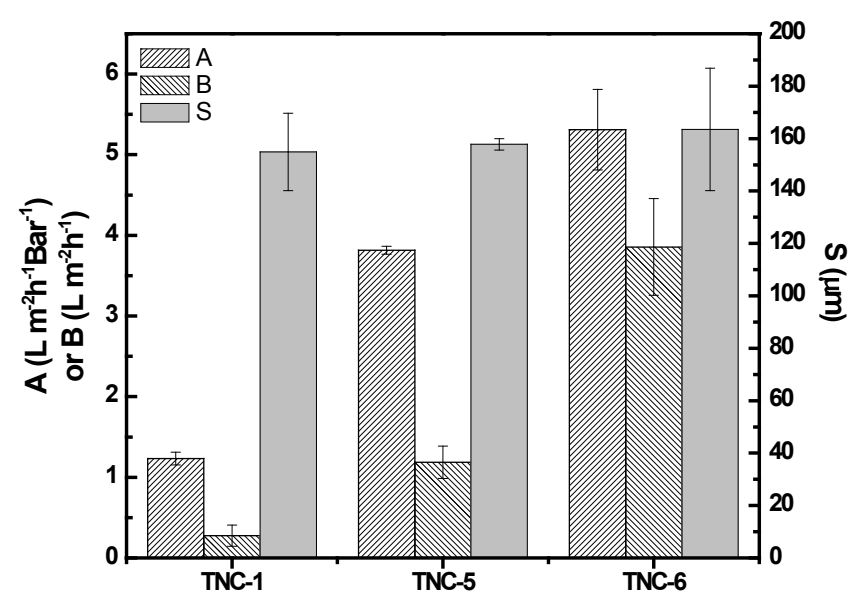

Figure 7: The membrane intrinsic parameters of TNC membranes without $\mathrm{NaClO}$ treatment (TNC-1), with 1000ppm NaClO treatment (TNC-5) and with 2000 ppm NaClO treatment (TNC-6).

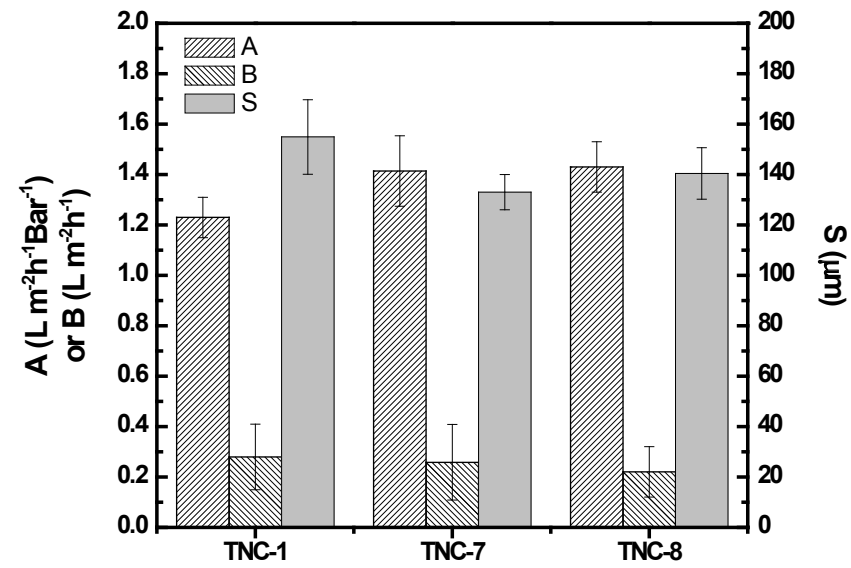

Figure 8: The membrane intrinsic parameters of TNC membranes with (TNC1) or without (TNC-7 and TNC-8) PET non-woven substrate. 


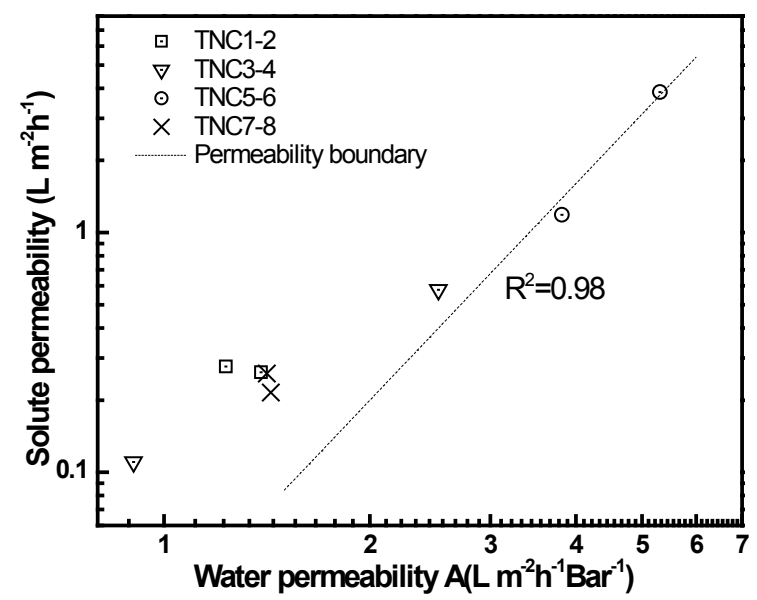

Figure 9: Trade-off relationship revealed by all TNC membranes fabricated in this study. All the A-B pairs can be fitted in the empirical relationship of $B=k^{*} A^{3}\left(k=0.025 \operatorname{Bar}^{3} m^{4} h^{2} L^{-2}\right)$.

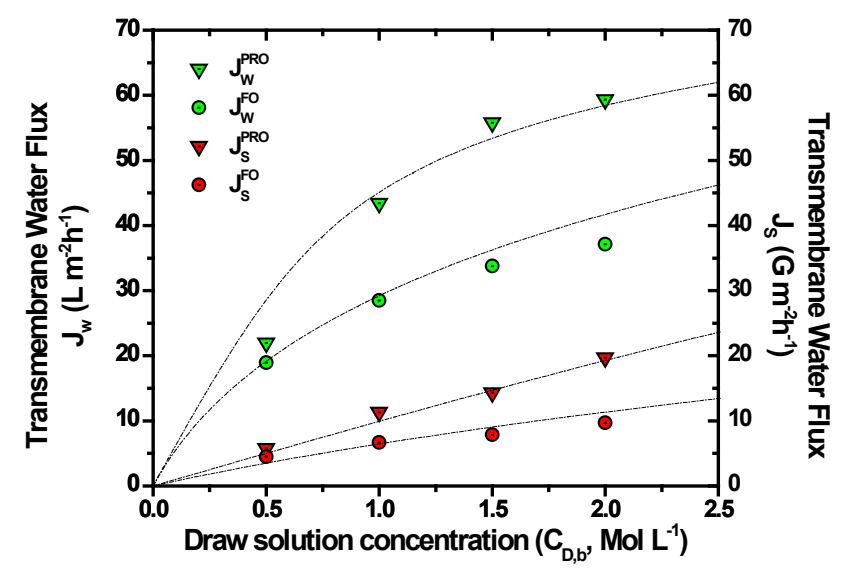

Figure 10: Performance of TNC-2 membrane in FO and PRO orientation (vertical axis) as a function of $C_{D, b}$. $C_{D, b}(\mathrm{NaCl})$ was varied from $0.5 \mathrm{M}$ to $2 \mathrm{M}$ while the feed solution concentration was maintained at $1 \mathrm{mM}$.

membrane selectivity and is related to the FO performance of TNC membranes.

\section{Relating TNC membrane intrinsic parameters with FO performance}

Typical behavior of water/solute flux as $\mathrm{CD}, \mathbf{b}$ increases: The typical FO water flux of the TNC-FO membrane (TNC-2) is plotted in Figure 10. The green triangles represent the experimental water flux $\left(J_{W}^{P R O}\right)$ in the PRO orientation. The concentrations of $\mathrm{NaCl}$ draw solution range from $0.5 \mathrm{M} \mathrm{NaCl}$ to $2 \mathrm{M} \mathrm{NaCl}$. The resulted $J_{W}^{P R O}$ ranged from $22.0 \mathrm{~L} \mathrm{~m}^{-2} \mathrm{~h}^{-1}$ to as high as $59.3 \mathrm{~L} \mathrm{~m}^{-2} \mathrm{~h}^{-1}$. While switched to FO orientation (green circles, $J_{W}^{F O}$ ), the resulted $J_{W}^{F O}$ was from $19.0 \mathrm{~L} \mathrm{~m}^{-2} \mathrm{~h}^{-1}$ to $37.1 \mathrm{~L} \mathrm{~m}^{-2} \mathrm{~h}^{-1}$ over the same range of concentration. The lower $J_{W}^{F O}$ compared with $J_{W}^{P R O}$ was believed to be attributed by more severe ICP at FO orientation [1]. It was also believed that the lower-than-expect water flux of FO membrane was mainly contributed by ICP rather than by ECP [41]. With the increase of $C_{D, b}$, both of $J_{W}^{P R O}$ and $J_{W}^{F O}$ increases initially at low $C_{D, b}$, but then leveled off at high $C_{D, b}$. This phenomenon has been described as "self-limiting" water flux behavior, and was believed to be caused by ICP induced by inefficiency of solute diffusion in support membrane [16]. The solute fluxes increase with similar trends of water fluxes: at PRO orientation, $J_{S}^{P R O}$ increased from $5.79 \mathrm{~g} \mathrm{~m}^{-2} \mathrm{~h}^{-1}$ to $19.69 \mathrm{~g} \mathrm{~m}^{-2} \mathrm{~h}^{-1}$ over the solute range tested; while at FO orientation, $J_{S}^{F O}$ increased from $4.49 \mathrm{~g} \mathrm{~m}^{-2}$ $\mathrm{h}^{-1}$ to $9.71 \mathrm{~g} \mathrm{~m}^{-2} \mathrm{~h}^{-1}$.

Relating water/solute flux to water/solute permeability coefficients: In Figure 11, the value $n R_{g} T^{\star} J_{S} / J_{W}$ (vertical axis) is plotted against the $B / A$ value (horizontal axis). At low $B / A$ values, all the data points lies near the line where $n R_{g} T^{\star} J_{S} / J_{W}=B / A$. This suggests that flux behavior fulfills the $S-D$ model suggested by Equation 4 very well $[14,34]$. This behavior is consistent with the validation of using the $B / A$ as the indicator of the separation ability of the membrane, as the $J_{S} / J_{W}$ stands for the unit of solute sacrificed to produce per unit of clean water. However at high $B / A$ values, the values of $n R T^{*} J_{S} / J_{W}$ tends to deviate from fitted line. The bigger value of $n R_{g} T^{\star} J_{S} / J_{W}$ than $B / A$, especially at high membrane permeabilities, may reflect that $J_{S} / J_{W}$ is no longer linearly related with $B / A$ when solute rejection is low. The non-linear increase of $n R_{g} T^{*} J_{S} / J_{W}$ is likely to be cause by 1) the non-ideal solutiondiffusion transportation of the solutes and 2) the coupled effects of the reverse solute permeation and the internal concentration polarization.

Relating membrane performance to water/solute permeability coefficients: For all the membranes, the summarized membrane performance $\left(J_{W}^{P R O}, J_{S}^{P R O}, J_{W}^{F O}\right.$ and $J_{S}^{F O}$ on vertical axis) is plotted as a function of $B / A$ (horizontal axis) in Figure 12. When $\mathrm{C}_{\mathrm{D}, \mathrm{b}}=0.5 \mathrm{M} \mathrm{NaCl}$ (upper left), the $J_{W}^{P R O}$ and $J_{W}^{F O}$ generally increase as $B / A$ increases. This can be interpreted as higher $A$ value of membrane allows more water to pass through the membrane. When $\mathrm{C}_{\mathrm{D}, \mathrm{b}}=2 \mathrm{M} \mathrm{NaCl}$ (upper right), the $J_{W}^{P R O}$ and $J_{W}^{F O}$ increases first and then decreases while $B / A$ value is excessively high. For example, $J_{W}^{P R O}$ and $J_{W}^{F O}$ for TNC-5 $(B / A=0.36)$ is $91.2 \mathrm{~L} \mathrm{~m}^{-2} \mathrm{~h}^{-1}$ and $60.9 \mathrm{~L}$ $\mathrm{m}^{-2} \mathrm{~h}^{-1}$ respectively. However when $B / A$ was further increased to 0.73 (i.e. TNC-6), the value of $J_{W}^{P R O}$ and $J_{W}^{F O}$ decreased to $86.9 \mathrm{~L} \mathrm{~m}^{-2}$ $\mathrm{h}^{-1}$ and $57.9 \mathrm{~L} \mathrm{~m}^{-2} \mathrm{~h}^{-1}$, respectively. This phenomenon of $J_{W}$, due to a synergistic effect of solute leakage and convective $J_{W}$ induced concentration polarization, will be analyzed and explained later. The

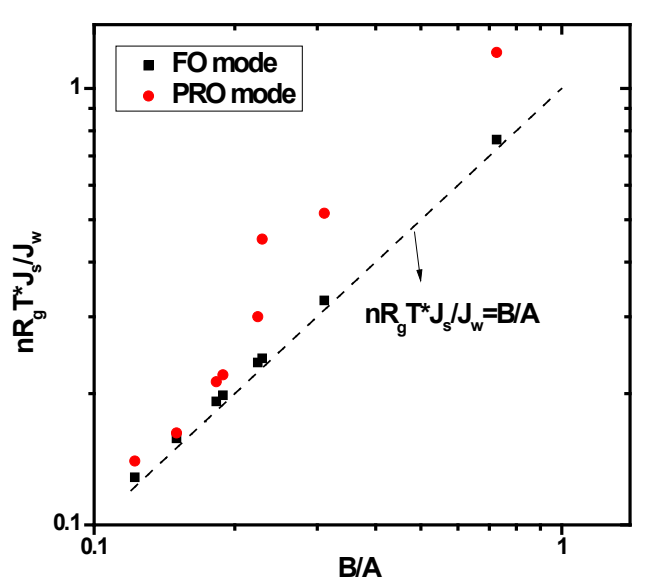

Figure 11: Linear fitting of $n R T^{*} J_{s} / J_{w}$ (vertical axis) as a function of $B / A$ (horizontal axis). 


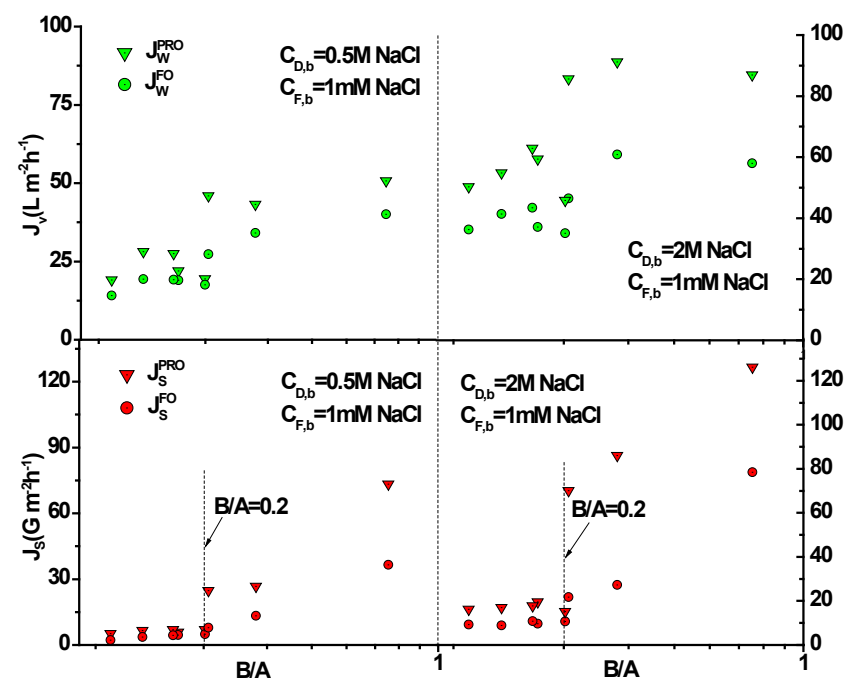

Figure 12: The FO performance of TNC membranes (vertical axis) as a function of $B / A$ (horizontal axis) with $C_{D, b}=0.5 \mathrm{M} \mathrm{NaCl}$ (one the left) and $C_{D, b}=2$ $\mathrm{M} \mathrm{NaCl}$ (on the right).

solute fluxes, $J_{S}^{P R O}$ and $J_{S}^{F O}$, constantly increased with bigger $B / A$ value. It is worth to note that beyond $B / A=0.2$, only a little increase of of $B / A$ results in substantial increase of both $J_{S}^{P R O}$ and $J_{S}^{F O}$. To conclude, although the more permeable (higher $B / A$ value) enjoys higher $J_{W}$, this enhancement generally reaches a plateau when $B / A$ is larger than 0.2. Concurrently, $J_{S}$ was observed to increased substantially beyond $B / A=0.2$ and resulted in limiting, or even deterioration effect for $J_{W}$. Thus from economical angle, FO membranes should generally have $B / A<0.2$ to minimize the uneconomical loss of draw solutes due to reverse diffusion (Supplementary Figure 1).

\section{Relating membrane intrinsic properties with ICP and ECP indexes}

Using experimentally determined $J_{S}, J_{W}, A, B, S$ values, the ICP and ECP indexes of FO orientation and PRO orientation can be derived by Equation 9, 10 and 11. Study of the CP indexes reveals the severity of undermined solute concentration by the according ICP and ECP phenomena. In the PRO orientation, both of ICP and ECP indexes are modeled [21,42]. However, in FO orientation, only the ICP is modeled while the ECP is considered paltry [16]. The value of ICP index is defined as the portion of $\Delta \pi_{\text {eff }}$ loss, which is either due to the dilutive ICP $\left(\mathrm{I}_{\mathrm{FO}}, \mathrm{FO}\right.$ orientation) or concentrative ICP $\left(\mathrm{I}_{\mathrm{PRO}}, \mathrm{PRO}\right.$ orientation $)$, divided by the osmotic pressure difference between the bulk draw and feed solutions. The value of ECP index is defined as the portion of $\Delta \pi_{\text {eff }}$ loss due to external dilution, divided by the bulk osmotic pressure difference. The $\mathrm{I}_{\mathrm{FO}}, \mathrm{I}_{\mathrm{PRO}}$ or $\mathrm{E}_{\mathrm{PRO}}$ is plotted as a function of $B / A$ in Figure 13. At both draw solution concentrations, $I_{\mathrm{FO}}$ generally increased with bigger $B / A$. This is because: a) bigger $B / A$ values indicate more solute leakage, leading to exacerbated dilutive ICP; b) according to the "trade-off" relationship between $A$ and $B$ values, higher water permeability always accompanies enhanced $B / A$ value. As a result, higher convective water flux $\mathrm{J}_{\mathrm{W}}$ exacerbated the dilutive ICP, as can be interpreted in Equation 11 that the ICP factor (i.e. $\left.1-\exp \left(-J_{W}^{F O} S / D\right)\right)$ is increased [16,43]. Similar explanations can be made to the trends of $\mathrm{E}_{\mathrm{PRO}}$ and $\mathrm{I}_{\mathrm{PRO}}$.

The $\mathrm{E}_{\mathrm{PRO}}$ (green solid circles) and $\mathrm{I}_{\mathrm{FO}}$ (red solid circles) exhibited similar trends and magnitude. The formulas in Equation 11 and Equation 13 to calculate the two indexes are identical, as the two phenomena both result from dilution by the convective $J_{W^{*}}$. However, the physical meaning of the ECP and ICP factor is different: the $\mathrm{k}$ in the ECP factor, $\left(1-\exp \left(-J_{W}^{P R O} / k\right)\right)$, stands for mass transfer coefficient in bulk solution; while the $D / S$ in the ICP factor, $\left(1-\exp \left(-J_{W}^{F O} /(D / S)\right.\right.$ ), stands for mass transfer coefficient in support membrane. The resistance of the support membrane always results in lower mass transfer coefficient than in the bulk solution, thus the value of $J_{W}^{F O}$ is constantly lower than the value of $J_{W}^{P R O}$ [16]. Since the $D$ value was kept as constant (i.e. solute type and temperature kept the same) [27], the deviation between $J_{W}^{F O}$ and $J_{W}^{P R O}$ is determined by the $S$ value of the FO membrane. When support membrane is thick and dense (i.e. big $S$ value), the ICP factor is much bigger than ECP factor, resulting in more severe dilution in the support membrane. The mass transfer coefficient in support membrane, $D / S$, is inefficient to restore the solute concentration in the support membrane, resulting in much lower $J_{W}^{F O}$ compared to $J_{W}^{P R O}[16,18]$. This scenario happens in conventional composite polyamide membranes fabricated by phase-inversion methods with $S$ value ranging from 300-3000 $\mu \mathrm{m}$ [11]. However, when support membrane is porous and thin (i.e. small $S$ value), the ICP factor approaches ECP factor, resulting in less discrepancy between $J_{W}^{F O}$ and $J_{W}^{P R O}$. This explains why $J_{W}^{F O}$ and $J_{W}^{P R O}$ for TNC membranes

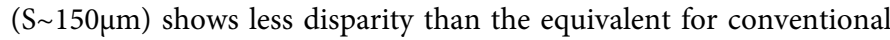
polyamide composite membranes [5-7,44]. As a result, the $I_{F O}$ and $E_{P R O}$ have similar magnitude, as they are reflections of $J_{W}^{F O}$ and $J_{W}^{P R O}$ respectively.

Compared with $I_{F O}$ and $E_{P R O}$, the value of $I_{\mathrm{PRO}}$ is substantially smaller, especially at low $B / A$ value (Figure 13 ). For example, when $B /$ $A=0.19$ (TNC-2 membrane), the $I_{P R O}$ was merely 0.007 , while $I_{F O}$ and $E_{P R O}$ was 0.42 and 0.35 , respectively. Even at the highest $B / A$ value investigated in this paper ( 0.73 , TNC- 6 membrane), the $I_{P R O}$ was merely 0.16 , while $I_{F O}$ and $E_{P R O}$ was 0.70 and 0.52 , respectively. It was observed that the significance of $\mathrm{I}_{\mathrm{PRO}}$ literally increases with higher $B / A$ value. Because $C_{F b}$ was kept constantly at $1 \mathrm{mM}$, the $I_{P R O}$ increase should be contributed by more severe leakage of solutes into support membrane according to Equation 12. However, the substantially smaller value of $I_{P R O}$ compared with $E_{P R O}$ reveals that the external convective dilution causes more severe $\Delta \pi_{\text {eff }}$ loss compared with internal concentration

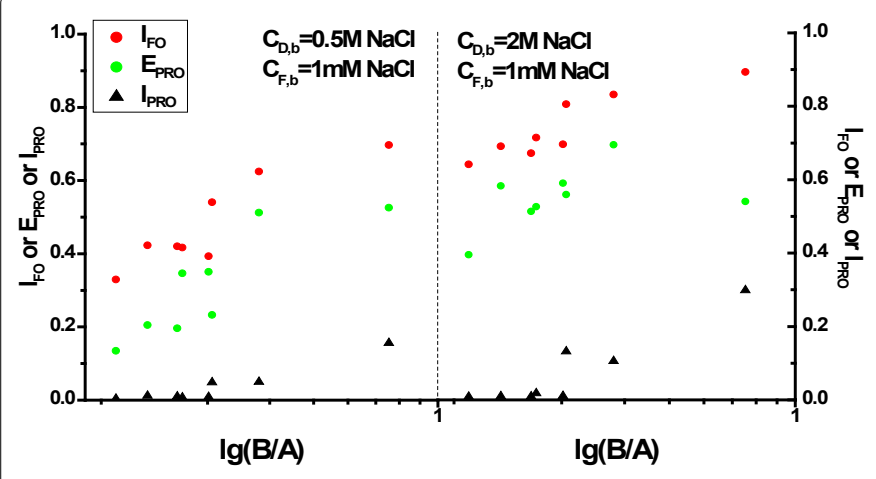

Figure 13: The ICP and ECP indexes of TNC membranes as a function of $B / A$ with $\mathrm{C}_{\mathrm{D}, \mathrm{b}}=0.5 \mathrm{M} \mathrm{NaCl}$ (one the left) and $\mathrm{C}_{\mathrm{D}, \mathrm{b}}=2 \mathrm{M} \mathrm{NaCl}$ (on the right). 
polarization. This implicates that the high $J_{W}$ has become the main restriction of membrane performance.

To conclude this section, when dilute feed solution was used, $\Delta \pi_{\text {eff }}$ loss to coupling of convective dilution with mass transfer coefficient in support membrane (i.e., $D / S$ value) is the most severe, resulting in lower $J_{W}^{F O} . \Delta \pi_{\text {eff }}$ loss to coupling of convective dilution with mass transfer coefficient in bulk solution (i.e., $k$ value) is less severe, resulting in higher $J_{P R O} . \Delta \pi_{\text {eff }}$ loss to coupling of leakage of solutes with mass transfer coefficient in support membrane (i.e. $D / S$ value) is minor.

\section{Conclusion}

A series of TNC membranes have been fabricated/modified by means of $\mathrm{NaOH}$ treatment, IP additives, chlorine post treatment, or removal of non-woven PET substrates. These membranes have varied water/solute permeability. It was found that A-B pairs of all the membranes can be fitted into the empirical relationship of $B=k^{*} A^{3}$ ( $k=0.025$ $\left.\mathrm{Bar}^{3} m^{4} h^{2} L^{-2}\right)$. That means any increase of water permeability of polyamide composite membrane accompanies concurrent increase of solute permeability. This "trade-off" relationship between water/solute permeability is closely related to the FO membrane performance. When $B / A$ is low, both of $J_{W}$ and $J_{S}$ is low; when $B / A$ is enhanced, $J_{W}$ will be increased substantially at the beginning but eventually level off and even be decreased. This results from a) the increase of $J_{W}$ also exacerbate the convective dilution ("self-limiting" phenomenon); and b) bigger $B / A$ value deteriorates the membrane selectivity, thus more severe leakage of solutes exacerbate the ICP within support membrane. The comparison between ICP index in FO orientation, $\mathrm{I}_{\mathrm{FO}}$, ECP index in $\mathrm{PRO}$ orientation, $\mathrm{E}_{\mathrm{PRO}}$, and $\mathrm{ECP}$ index in FO orientation, $\mathrm{I}_{\mathrm{PRO}}$, reveals that convective dilution by $J_{W}$ itself is the main restriction of further $J_{W}$ increase. The coupling of convective dilution with diffusion resistance in support membrane ( $S$ value) resulted in further decreased $J_{W}^{F O}$ compared to $J_{W}^{P R O}$. However, the decrease has been minimized because of low $S$ value of TNC membranes $(\sim 150 \mu \mathrm{m})$. The leakage of solutes into support membrane causes accumulative ICP, however its value is minor compared with convective dilution.

\section{Acknowledgements}

This work was supported by the Prime Minister's Office of Singapore via an initiative called The Enterprise Challenge under award number P00579/1273, Singapore Environment \& Water Industry (EWI) Development Council under award number MEWR 621/06/166. The authors also acknowledge the financial support from Public Utilities Board of Singapore under the R\&D grant (IDD90301/001/75).

\section{References}

1. Cath TY, Childress AE, Elimelech M (2006) Forward osmosis: Principles, applications, and recent developments. J Mem Sci 281: 70-87.

2. Pan SF, Dong $Y$, Zheng YM, Zhong LB, Yuan ZH (2017) Self-sustained hydrophilic nanofiber thin film composite forward osmosis membranes: Preparation, characterization and application for simulated antibiotic wastewater treatment. J Mem Sci 523: 205-215.

3. Yang Q, Lei J, Sun DD, Chen D (2016) Forward Osmosis Membranes for Water Reclamation. Sep Purifi Reviews 45: 93-107.

4. Huang L, Arena JT, McCutcheon JR (2016) Surface modified PVDF nanofiber supported thin film composite membranes for forward osmosis. J Mem Sci 499 352-360.

5. Wei J, Liu X, Qiu C, Wang R, Tang CY (2011) Influence of monomer concentrations on the performance of polyamide-based thin film composite forward osmosis membranes. J Mem Sci 381: 110-117.

6. Wang R, Shi L, Tang CY, Chou S, Qiu C, et al. (2010) Characterization of novel forward osmosis hollow fiber membranes. J Mem Sci 355: 158-167.
7. Yip NY, Tiraferri A, Phillip WA, Schiffman JD, Elimelech M (2010) High Performance Thin-Film Composite Forward Osmosis Membrane. Environ Sc Technol 44: 3812-3818.

8. Widjojo N, Chung TS, Weber M, Maletzko C, Warzelhan V (2011) The role of sulphonated polymer and macrovoid-free structure in the support layer for thin-film composite (TFC) forward osmosis (FO) membranes. J Mem Sci 383: 214-223.

9. Wang KY, Chung TS, Amy G (2012) Developing thin-film-composite forward osmosis membranes on the PES/SPSf substrate through interfacial polymerization. AIChE J 58: 770-781.

10. Arena JT, McCloskey B, Freeman BD, McCutcheon JR (2011) Surface modification of thin film composite membrane support layers with polydopamine: Enabling use of reverse osmosis membranes in pressure retarded osmosis. $J$ Mem Sci 375: 55-62.

11. Yip NY, Elimelech M (2011) Performance Limiting Effects in Power Generation from Salinity Gradients by Pressure Retarded Osmosis. Environ Sci Techno 45: 10273-10282.

12. Song X, Liu Z, Sun DD (2011) Nano Gives the Answer: Breaking the Bottleneck of Internal Concentration Polarization with a Nanofiber Composite Forward Osmosis Membrane for a High Water Production Rate. Adv Mater 23: 3256-3260.

13. Bui NN, Lind ML, Hoek EMV, McCutcheon JR (2011) Electrospun nanofiber supported thin film composite membranes for engineered osmosis. J Mem Sci 386: 10-19.

14. Tang CY, She Q, Lay WCL, Wang R, Field R, et al. (2011) Modeling doubleskinned FO membranes. Desalination 283: 178-186.

15. Geise GM, Park HB, Sagle AC, Freeman BD, McGrath JE (2011) Wate permeability and water/salt selectivity tradeoff in polymers for desalination. $J$ Mem Sci 369: 130-138.

16. McCutcheon JR, Elimelech M (2006) Influence of concentrative and dilutive internal concentration polarization on flux behavior in forward osmosis. J Mem Sci 284: 237-247.

17. Tiraferri A, Yip NY, Phillip WA, Schiffman JD, Elimelech M (2011) Relating performance of thin-film composite forward osmosis membranes to support layer formation and structure. J Mem Sci 367: 340-352.

18. McCutcheon JR, Elimelech M (2008) Influence of membrane support laye hydrophobicity on water flux in osmotically driven membrane processes. J Mem Sci 318: 458-466.

19. Ghosh AK, Jeong BH, Huang X, Hoek EMV (2008) Impacts of reaction and curing conditions on polyamide composite reverse osmosis membrane properties. J Mem Sci 311: 34-45.

20. Loeb S, Titelman L, Korngold E, Freiman J (1997) Effect of porous support fabric on osmosis through a Loeb-Sourirajan type asymmetric membrane. Mem Sci 129: 243-249.

21. Yip NY, Tiraferri A, Phillip WA, Schiffman JD, Hoover LA, et al. (2011) Thin-Film Composite Pressure Retarded Osmosis Membranes for Sustainable Power Generation from Salinity Gradients. Environ Sci Technol 45: 4360-4369.

22. Lee KL, Baker RW, Lonsdale HK (1981) Membranes for power generation by pressure-retarded osmosis. J Mem Sci 8: 141-171.

23. Phillip WA, Yong JS, Elimelech M (2010) Reverse Draw Solute Permeation in Forward Osmosis: Modeling and Experiments. Environ Sci Technol 44: 5170 5176

24. Tang CY, She Q, Lay WCL, Wang R, Fane AG (2010) Coupled effects of internal concentration polarization and fouling on flux behavior of forward osmosis membranes during humic acid filtration. J Mem Sci 354: 123-133.

25. Muthumareeswaran MR, Agarwal GP (2014) Feed concentration and pH effect on arsenate and phosphate rejection via polyacrylonitrile ultrafiltration membrane. J Mem Sci 468: 11-19.

26. Song X, Liu Z, Sun DD (2013) Energy recovery from concentrated seawater brine by thin-film nanofiber composite pressure retarded osmosis membranes with high power density. Energy Environ Sci 6: 1199-1210.

27. Achilli A, Cath TY, Childress AE (2010) Selection of inorganic-based draw solutions for forward osmosis applications. J Mem Sci 364: 233-241.

28. Strathmann H, Kock K (1977) The formation mechanism of phase inversion membranes. Desalination 21: 241-255. 
Citation: Xiaoxiao S, Prince JA, Sun DD (2016) Relating Water/Solute Permeability Coefficients to the Performance of Thin-Film Nanofiber Composite Forward Osmosis Membrane. J Membra Sci Technol 6: 160. doi:10.4172/2155-9589.1000160

29. Kim SH, Kwak SY, Suzuki T (2005) Positron Annihilation Spectroscopic Evidence to Demonstrate the Flux-Enhancement Mechanism in MorphologyControlled Thin-Film-Composite (TFC) Membrane. Environ Sci Technol 39: 1764-1770.

30. Gibson PW, Schreuder-Gibson HL, Rivin D (1999) Electrospun fiber mats: Transport properties. AIChE J 45: 190-195.

31. Feng C, Khulbe KC, Matsuura T, Gopal R, Kaur S, et al. (2008) Production of drinking water from saline water by air-gap membrane distillation using polyvinylidene fluoride nanofiber membrane. J Mem Sci 311: 1-6.

32. Tasuku O, Ding B, Sone Y, Shiratori S (2007) Super-hydrophobic surfaces of layer-by-layer structured film-coated electrospun nanofibrous membranes. Nanotechnology 18: 165607.

33. Thavasi V, Singh G, Ramakrishna S (2008) Electrospun nanofibers in energy and environmental applications. Energy Environ Sci 1: 205-221.

34. Qiu C, Qi S, Tang CY (2011) Synthesis of high flux forward osmosis membranes by chemically crosslinked layer-by-layer polyelectrolytes. J Mem Sci 381: 74

35. Zhang G, Yan H, Ji S, Liu Z (2007) Self-assembly of polyelectrolyte multilayer pervaporation membranes by a dynamic layer-by-layer technique on a hydrolyzed polyacrylonitrile ultrafiltration membrane. J Mem Sci 292: 1-8.

36. Gupta ML, Gupta B, Oppermann W, Hardtmann G (2004) Surface modification of polyacrylonitrile staple fibers via alkaline hydrolysis for superabsorbent applications. J App Poly Sci 91: 3127-3133.

37. Yung L, Ma H, Wang X, Yoon K, Wang R, et al (2010) Fabrication of thin-film nanofibrous composite membranes by interfacial polymerization using ionic liquids as additives. J Mem Sci 365: 52-58

38. Do VT, Tang CY, Reinhard M, Leckie JO (2012) Degradation of Polyamide Nanofiltration and Reverse Osmosis Membranes by Hypochlorite. Environ Sci Technol 46: 852-859.

39. Kwon YN, Leckie JO (2006) Hypochlorite degradation of crosslinked polyamide membranes: II. Changes in hydrogen bonding behavior and performance. $J$ Mem Sci 282: 456-464.

40. Lau WJ, Ismail AF, Misdan N, Kassim MA (2012) A recent progress in thin film composite membrane: A review. Desalination 287: 190-199.

41. McCutcheon JR, McGinnis RL, Elimelech M (2006) Desalination by ammoniacarbon dioxide forward osmosis: Influence of draw and feed solution concentrations on process performance. J Mem Sci 278: 114-123.

42. Su J, Chung TS (2011) Sublayer structure and reflection coefficient and their effects on concentration polarization and membrane performance in FO processes. J Mem Sci 376: 214-224.

43. Li W, Gao Y, Tang CY (2011) Network modeling for studying the effect of support structure on internal concentration polarization during forward osmosis: Model development and theoretical analysis with FEM. J Mem Sci 379: 307-321.

44. Zhang S, Wang KY, Chung TS, Chen H, Jean YC, et al. (2010) Wellconstructed cellulose acetate membranes for forward osmosis: Minimized internal concentration polarization with an ultra-thin selective layer. J Mem Sci 360: $522-535$ 